\title{
Associations between Baseline Vitamin D Status, Dietary Intake of Vitamin D and Calcium on Bone Health in Caucasian and South Asian Women: Further analysis of the D2-D3 Study
}

\author{
S. Kisi ${ }^{1}$, L. Tripkovic ${ }^{1}$, K.H. Hart ${ }^{1}$, L.R. Wilson ${ }^{1}$ and S.A. Lanham-New ${ }^{1}$ \\ ${ }^{1}$ Nutritional Sciences Department, School of Biosciences and Medicine, Faculty of Health \& Medical Sciences, \\ University of Surrey, Guildford, GU2 7XH, UK
}

Vitamin D deficiency results in osteomalacia and leads to osteoporosis. ${ }^{(1,2)}$ Hypo-vitaminosis D is prevalent in the UK and our D-FINES study has shown vitamin D deficiency to be more common in South Asian (SA) women than Caucasian (CA) women living in South England ${ }^{(3)}$.

The aim of this study was to investigate the relationship between dietary vitamin D and calcium (Ca) intakes, vitamin D status and bone health indices among the women who took part in our D2-D3 study. The D2-D3 study was a vitamin D RCT previously reported $^{(4)}$ in which vitamin D status was measured by LC/MS and $4 \mathrm{~d}$ food diaries were used to measure dietary intake. The specific cross-sectional analysis was on the baseline data of 260 women and the longitudinal analysis on 59 women in the placebo group.

Mean dietary vitamin D intakes in SA and CA women were $2 \cdot 24 \pm 2.0,2.78 \pm 2.3 \mu \mathrm{g}$, respectively. Mean dietary Ca intakes were $870 \pm 261.5 \mathrm{mg}$ in Caucasians and $703.5 \pm 211.5 \mathrm{mg}$ in South Asians. Vitamin D status of Caucasians $(60.21 \pm 25.6 \mathrm{nmol} / \mathrm{l})$ was much higher than that of Asians $(21.7 \pm 18.1 \mathrm{nmol} / \mathrm{l}),(\mathrm{P}<0.001)$. Body weight and body fat in Asians and BMI in Caucasians were negatively correlated with serum 25 -hydroxyvitamin $\mathrm{D}$ status $(25 \mathrm{OHD})(\mathrm{P}<0.05)$. In $\mathrm{SA}$ women, higher vitamin $\mathrm{D}$ intake was associated with higher vitamin D status (lowest vitamin D intake T1, 25(OH)D $16.35 \mathrm{nmol} / 1$ to highest vitamin D intake T3, 25(OH)D 35.08 $\mathrm{nmol} / 1 ; \mathrm{F}$ test for linearity, $\mathrm{P}=0.017)$, remaining significant after adjusting for age and body size $(\mathrm{P}<0.01)$. When $\mathrm{Ca}$ and vitamin $\mathrm{D}$ intakes were analysed together; increased combined intakes of $\mathrm{Ca}$ and vitamin $\mathrm{D}$ resulted in higher $25(\mathrm{OH}) \mathrm{D}$ (low Ca-low vitamin $\mathrm{D}$, $25(\mathrm{OH}) \mathrm{D} 16.14 \mathrm{nmol} / \mathrm{l}$ to high Ca-high vitamin D, 25(OH)D $28.4 \mathrm{nmol} / \mathrm{l} ; \mathrm{F}$ test for linearity, $\mathrm{P}<0.05)$, and this relationship remained significant after adjustments for body size $(\mathrm{P}<0.05)$ in the SA women. As shown in the Figures below, increased Ca intakes resulted in higher BMC, in spite of the decreased vitamin D intakes (Medium Ca-High Vitamin D, BMC $=0.9070 \mathrm{~g} / \mathrm{cm}$ to High Ca-Medium Vitamin $\mathrm{D}, \mathrm{BMC}=1.1613 \mathrm{~g} / \mathrm{cm}$; F test for linearity, $\mathrm{P}<0.01)$ in POST-CA women. Women in the placebo group of the D2D3 study with vitamin D deficiency at baseline had a less pronounced decrease in vitamin D status during winter.

These results demonstrate the importance of dietary $\mathrm{Ca}$ to bone health and the synergistic beneficial effects of combined dietary $\mathrm{Ca}$ and vitamin D intakes on vitamin D status and bone health. Further work is required on endogenous and exogenous factors affecting longitudinal changes in vitamin D status throughout the year.
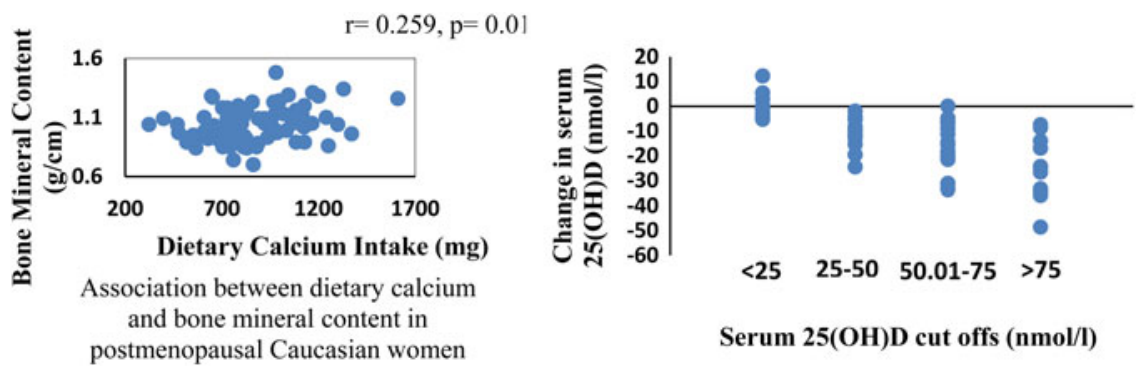

Serum 25(OH)D cut offs $(\mathrm{nmol} / \mathrm{l})$

The D-FINES study was funded by the FSA (N05064) and the D2-D3 study by the BBSRC DRINC programme (BB/I006192/1).

1. Scientific Advisory Committee on Nutrition (SACN) (2015) Vitamin D and Health Report (in press).

2. O'Mahony L et al. Nutrients 2011, 3, 1023-1041.

3. Darling A.L. et al. Osteoporos Int (2013) 24:477-488.

4. Tripkovic L. et al. Proceedings of the Nutrition Society 2015; 74 (OCE1), E16. 